\title{
Increasing world incidence of thyroid cancer: Increased detection or higher radiation exposure?
}

\author{
Leonard Wartofsky
}

Chairman, Department of Medicine, Washington Hospital Center, Professor of Medicine, Anatomy, Physiology \& Genetics, Uniformed Services University of the Health Sciences, Bethesda, Maryland, Professor of Medicine, Georgetown University School of Medicine, Washington, D.C., USA

\section{INTRODUCTION}

Thyroid cancer is the most common endocrine malignancy with more deaths annually than all other endocrine cancers combined. Medical centers in many parts of the world have noted an increasing frequency of cases of thyroid cancer. The general impression has been that if there is a rising frequency, it was likely due to some environmental cause, namely, greater radiation exposure or some other toxic exposure. This concept was dealt with in the publication of a statistical analysis of data from the Surveillance Epidemiology and End Results (SEER) database by Davies and Welch. ${ }^{1}$ This analysis indicated that the ostensible increase was actually due to increasing detection and not to a greater occurrence of papillary thyroid cancer. This review will explore this concept as well as examine the likelihood of an impact of

Key words: Follicular thyroid adenoma, Follicular thyroid carcinoma, Irradiation, Thyroid cancer

Address for correspondence:

Leonard Wartofsky, MD, MACP, Chairman, Department of Medicine, Washington Hospital Center, 110 Irving Street, N.W., Washington, DC 20010-2975 Tel.: 202-877-3109, FAX: 202-877-6292 e-mail: leonard.wartofsky@medstar.net Received 15-12-09, Accepted 10-03-10 environmental risk factors other than radiation exposure on thyroid cancer.

\section{GENERAL OVERVIEW OF EPIDEMIOLOGY}

Papillary thyroid carcinoma (PTC) is the most common of all endocrine malignancies and is the most highly differentiated cancer of the thyroid follicular epithelium. PTC tends to affect women more often than men, and in 2006 it was predicted to be one of the top seven leading causes of new cases of cancer in women, representing 3\% of all cancers in women, about $1 \%$ in men, ${ }^{2}$ and about $1.4 \%$ of all cancers in children. In general, approximately twothirds of thyroid cancer patients will be women (2: 1 ratio), although this will differ in other countries as compared to the USA. For example, the female: male ratio in Japan has been described as much as 13: $1{ }^{3}$ Thyroid cancer is very rare in children under age 15 , representing $1.5-3 \%$ of all childhood cancers, but initial presentation may be as early as at 5 years of age. In North American children, incidence rates are 0.9 per million boys and 2.2 per million girls, ${ }^{4}$ with the sex ratio being relatively equal until puberty. In adolescence, the $\mathrm{F} / \mathrm{M}$ ratio may be as high as 2.56:1, and most of these tumors are PTC. The extreme sensitivity of children's thyroid gland to radiation is exemplified by the epidemic of thyroid cancer in children exposed to radiation in Belarus in 1986, presumably because the 'younger' thyroid gland undergoes more rapid growth and cellular proliferation. 
This is even more the case in the presence of iodine deficiency, a situation that pertains to Belarus and the surrounding area (see below). Thyroid cancer may also present in the extreme later decades of life, although most patients will present between the ages 25 and 55. If the increasing incidence is due to detection, then it follows that theoretically the longer one lives the greater the likelihood of detection. Indeed, the annual incidence of thyroid cancer increases with age, and then peaks between $100-120 / 10^{6}$ by the fifth to eighth decades of life. ${ }^{5}$

Prognosis worsens after age 45 , which accounts for the change in staging of thyroid cancers based upon whether the diagnosis is initially made before or after the 45th birthday. The American Cancer Society estimated 37,200 new cases of thyroid cancer in 2009 with approximately 1600 deaths occurring amongst the estimated 300,000 patients with the disease in the USA. It is anticipated that this will rise further. The possible basis for increasing detection as accounting for the higher frequency of thyroid cancer is related in part to earlier diagnosis due to use of ultrasound and fine needle aspiration (FNA) cytology of thyroid nodules, particularly in regard to nodules found incidentally during other imaging techniques such as computerized tomography (CT), magnetic resonance imaging (MRI), FDG-positron emission tomography (PET) scanning or Doppler ultrasonography. However, the potential etiologic role of increasing exposure to ionizing radiation deserves careful examination. As mentioned above, a recent analysis alleges that the increase is more apparent than real and is simply due to better detection. ${ }^{1}$ This retrospective analysis of the SEER database from 1973 to 2002 confirmed a 2.4 fold rise in incidence from 3.6/100,000 in 1973 to $8.7 / 100,000$ in 2002. Indeed, the latter analysis ascribed the mounting frequency of cases almost totally to cases of PTC and not to any of the other variants of thyroid cancer. Meanwhile, most of the PTCs identified were small, often microcarcinomata, $49 \%$ being $<1 \mathrm{~cm}$ in diameter and $87 \%$ being $<2 \mathrm{cms}$. Given that there was no observed rise in mortality during this time interval $(0.5 / 100,000)$, the authors concluded that the observed increase was due to greater rates of detection over the past several decades and not to actual increases in occurrence. PTC accounts for $65-80 \%$ of all thyroid cancers ${ }^{5,6}$ and its increasing frequency relative to the incidence of follicular thyroid cancer (FTC) has been attributed to the higher iodine content of the American diet. Exposure to radiation as a risk factor for PTC is difficult to deny in the face of indications that the risk of malignancy in a thyroid nodule rises from 5-10\% up to 30-50\% with radiation exposure. ${ }^{7}$ Sources for radiation exposure, given the long latency and slow growth rates for thyroid cancer, could include the nuclear tests of the 1950s and 1960s as well as nuclear facility accidental releases such as at Chernobyl in 1986.

About a third of patients will have some underlying thyroid disease such as Hashimoto's disease or multinodular or adenomatoid goiter. In one series of 596 PTC patients, ${ }^{8} 40 \%$ of patients had other benign thyroid disease, $33 \%$ having coexistent thyroid nodules and $20 \%$ having Hashimoto's thyroiditis. Coexistent Hashimoto's disease may be a favorable prognostic factor for recurrence and survival. ${ }^{9}{ }^{910}$ Some familial PTCs occur in association with Hashimoto's thyroiditis, ${ }^{11,12}$ and a family history of thyroid cancer is important to elicit at presentation. One basis for this relationship has been found to be increased PI3K/ Akt expression which is elevated in both the chronic inflammation of Hashimoto thyroiditis and in well differentiated thyroid cancer..$^{13}$ In addition, the relative risk of thyroid cancer may be ten times higher in relatives of patients with thyroid cancer..$^{14}$ There may also be an increased risk of developing breast cancer in patients with Hashimoto's thyroiditis as well as in white (but not black) women with thyroid cancer (RR $=1.42$ ), although breast cancer patients do not have an increased risk of thyroid cancer. ${ }^{15,16}$

\section{GEOGRAPHIC CONSIDERATIONS}

Thyroid carcinoma is the most common of the endocrine cancers, with annual incidence rates ranging from 1 to 10 cases per 100,000 population, and (other than skin cancer) it accounts for $1.7 \%$ of all malignancies in the USA $(0.85 \%$ of cancers in men, $2.6 \%$ in women). ${ }^{2}$ Annual incidence rates of thyroid cancer will vary by geographic area, age, and sex. The age-adjusted annual incidence (for the period 1996 to 2000) in the United States was 68 new cases per million, ${ }^{5,6}$ with a higher incidence in women $(99$ per million) than men ( 36 per million). ${ }^{5,17}$ Worldwide, 
incidence rates of thyroid cancer may vary widely, with the causes potentially related to inherent racial or ethnic differences, geographical or environmental differences including iodine excess or deficiency, and possible radiation exposure. Rates have been observed to be high in certain geographic areas such as Hawaii (119 per million women and 45 per million men), ${ }^{5,18}$ particularly among Chinese and Filipinos, while rates in Poland are among the lowest recorded at 14/million women and 4/million men. ${ }^{19}$ The incidence of thyroid cancer is higher in Hawaii in each ethnic group than in their country of origin. The incidence of thyroid cancer in Chinese and Japanese living in the United States of America is two-fold the incidence in their country of origin. Indeed, although there is considerable variation in cancer incidence worldwide, ${ }^{20}$ reports of escalating incidence over the past several decades have come from all over the globe, including Italy, ${ }^{21}$ Iceland, ${ }^{22}$ Canada, ${ }^{23}$ USA, ${ }^{24}$ Australia, ${ }^{25}$ the South Pacific, ${ }^{26}$ and Europe. ${ }^{27,28}$

Given that there is more than sufficient evidence that the incidence of thyroid cancer, and PTC in particular, is increasing, what might be the reason or reasons for these observations? Davies and Welch ${ }^{1}$ have emphasized the greater likelihood of finding small incidental tumors by various imaging techniques. Related to this is the other important mechanism for detecting thyroid disease by actual screening techniques, and improved screening was believed to underlie the increasing frequency of detection in several geographic areas..$^{24,27,28}$

\section{DIETARY IODINE}

Dietary iodine intake is among the possible environmental influences on the incidence and prevalence of thyroid disease in general and thyroid cancer in particular. That an observed upsurge in the frequency of papillary carcinoma in Ireland might be related to increased dietary iodine intake was proposed by $\mathrm{Di}$ jkstra et al. ${ }^{29}$ These workers retrospectively reviewed data from 1970 to 2000 and observed a significant increase in PTC in parallel with increases in iodine intake. Indeed, a higher incidence of thyroid cancer has been noted in regions enjoying introduction of iodine prophylaxis against goiter, and a predominance of PTC over follicular thyroid cancer (FTC) in areas of iodine surfeit is well recognized, as is the association, on the other hand, of iodine deficiency with FTC. On the basis of the kinetics of iodine economy, it would be expected that the fractional iodine uptake of thyroid glands would be higher in patients living in regions of iodine deficiency. As a consequence, children in such areas of the world would be susceptible to higher absorbed doses of radioiodine in the event of nuclear accidents or other radiation exposure. Cardis et $\mathrm{al}^{30}$ estimated that the odds ratio for thyroid cancer with $1 \mathrm{~Gy}$ of exposure ranged from 5.5 to 8.4 and an iodine deficient diet potentiated the risk of cancer by three-fold. Importantly, dietary potassium iodide supplements reduced the risk by three-fold, even when the iodine was ingested as late as several months later.

\section{RADIATION AND RADIATION FALLOUT}

It is well acknowledged that the thyroid gland is unusually sensitive to both external and internal radiation, and of course radioiodine is employed therapeutically for diffuse and nodular toxic goiter and thyroid cancer. Indeed, the thyroid gland is arguably the only organ with a documented major rise in cancer incidence after radiation exposure, especially in children. Focal micropapillary hyperplasia has been found in the thyroids of children exposed at Chernobyl, likely representing a histopathologic precursor of carcinoma, and it is the children's exposure to fallout that constitutes the most logical explanation. General aspects of radiation injury to the thyroid gland, and the well documented history of the Chernobyl accident in April 1986 and its consequences, have been extensively reviewed ${ }^{31,32}$ and will not be discussed at any significant length here. Suffice it to say that a strong dose response curve has been observed based upon reconstructions of estimated radiation dosage exposure and dietary iodine intake. Cardis et $\mathrm{al}^{30}$ examined the records of children who were of age < 15 in April 1986 in Belarus and described the dose response curve for 276 confirmed cases of thyroid cancer. The median dose was 0.35 Gy with a maximum dose of $10.2 \mathrm{~Gy}$. The increased incidence clearly related to the nuclear accident, with incidence rates of thyroid cancer in children at Belarus $<15 \mathrm{yrs}$ at diagnosis rising from $0.3 / 10^{6}$ before the accident (1981-85) to $4.0 / 10^{6}$ between $1986-1990$, and up to 
30.6/10 ${ }^{6}$ between 1991-1994. In the region of Gomel Oblast, even more dramatic increases in incidence were seen in the same respective three time periods from $0.5 / 10^{6}$ to $10.5 / 10^{6}$ to $96.4 / 10^{6}$.

Other examples of thyroid malignancies, again typically only PTC, may develop as a result of radiation fallout due to nuclear weapons testing. Kerber et al ${ }^{33}$ studied 2473 individuals who had been exposed as children to fallout from nuclear weapons testing and who received doses ranging from $0-4600 \mathrm{mGy}$ and averaging $170 \mathrm{mGy}$. They found a statistically significant increase in both benign and malignant thyroid lesions, with a 400 mGy exposure being associated with a 3.4-fold relative risk. Both benign and malignant thyroid nodules were also well documented due to the fallout over the Marshall Islands in 1954. ${ }^{34}$ Indeed, thyroid cancer was the first malignancy discovered to have been associated with the atomic bombs dropped at Hiroshima and Nagasaki, and the presence of thyroid cancer in survivors could be directly linked to that exposure..$^{35,36}$

On the other hand, smaller amounts of radiation exposure, i.e. from either lower dosage of fallout ${ }^{37}$ or from diagnostic use of radioisotopes, have not been associated with a higher incidence of thyroid cancer. Thus, diagnostic 131-Iodine was not associated with thyroid neoplasia in a total of over 6000 children $^{38,39}$ or in another review of 2727 patients who received 131-Iodine therapy for hyperthyroidism. ${ }^{40}$

\section{EXTERNAL RADIATION EXPOSURE}

External radiation therapy for a variety of benign conditions of the head and neck was introduced between 1920 and 1950 in the United States. There is a linear relationship between radiation doses up to 1800 rads and the incidence of thyroid nodules and cancer. The increase in the risk of clinically significant thyroid cancer associated with prior radiotherapy to the head and neck given for thymic enlargement, tonsillitis, acne, and adenitis is around 3\%. ${ }^{41,42}$ As suggested above, radiation exposure during childhood is more likely to produce thyroid neoplasia than similar exposure at a later age, this possibly being related to greater cellular mitotic activity at the earlier age of insult. Among individuals in the U.S. receiving head and neck irradiation in childhood, palpable nodules are found in 16 to $29 \%$ and carcinoma in one third of these nodules. ${ }^{43}$ Most nodules tend to occur within 10 to 20 years of exposure, but the risk for nodule development and thyroid cancer may exist for over 40 years.

\section{ADDITIONAL FACTORS}

A few other factors that may potentially enhance risk for thyroid cancer deserve mention. One is the presence of antecedent benign thyroid disease, e.g. goiter, particularly multinodular goiter. Although several studies have found that goiter and benign thyroid adenomata reflect risk factors for subsequent thyroid cancer, there is a significant confounder in regard to recall bias in these studies. However, there is one linkage study that avoided such bias and did find that prior benign thyroid disease was a risk factor. ${ }^{44}$ A variety of other disorders may also be associated with thyroid cancer including Gardner's syndrome, familial adenomatous polyposis, Cowden syndrome, Carney complex, ${ }^{45}$ celiac disease, ${ }^{46}$ and obesity. ${ }^{47}$ Several in vivo and in vitro studies have implicated thyrotropin (TSH) as a mitogen, with higher TSH levels being associated with stimulation of growth of thyroid cancer cells and metastases, while more successful outcomes are associated with TSH suppression. ${ }^{48}$ Consequently, it was not too surprising to learn of studies indicating a correlation between age and TSH level with incidence of thyroid cancer ${ }^{49}$ and that pre-operative TSH levels were statistically significantly correlated with cancer risk and with stage of disease. ${ }^{50}$ These data may have implications and relevance to the increased frequency of thyroid cancer in Hashimoto thyroiditis patients who may have higher than normal TSH levels due to early gland failure or to relative iodine excess.

Gender as a risk factor for thyroid cancer has been puzzling, with most population studies showing a clearly increased risk in women, yet it seems that the disease may be more aggressive in men. It is notable that the pre-pubertal and post-menopausal incidence rates are not greater than in men. The female preponderance suggests that estrogen or other hormonal factors are involved-some studies showing a correlation between parity and incidence - with a greater risk of thyroid cancer with more pregnan- 
cies. A specific susceptibility gene with sex hormone receptor elements has been postulated.

\section{CONCLUSIONS}

There is absolutely no question that the incidence of thyroid cancer, and papillary thyroid carcinoma in particular, is increasing in many parts of the world. The data are suggestive, but not fully convincing, that the etiology of the increasing incidence is due solely to improved detection and screening. However, while man and pertinent technology may have become more adroit at detection, mankind has also enhanced risks of thyroid malignancy by interventions such as therapeutic radiation to the head and neck and nuclear fission with its radiation fallout. The resultant higher prevalence of thyroid cancer is further heightened by autoimmune phenomena, genetic mutation, alterations in iodine intake, and potential environmental carcinogens, both known and unknown. If the increase is simply due to improved detection, it is difficult to explain the observations that incidence appears to be increasing faster in developing countries (which can ill afford the expensive technology for detection) than in the West. Davies and Welch ${ }^{1}$ argue that the fact that cancer mortality has been stable over several decades might imply that most of the carcinomas detected may be papillary microcarcinomas found early enough to have an excellent prognosis. Is it also possible that the mortality rates are stable, in spite of increasing incidence, due to the improved approaches to management and therapy that accompanied development of highly sensitive thyroglobulin assays, recombinant human thyrotropin, FDG-PET scanning, and better understanding of the natural history of thyroid cancer. These questions will hopefully be resolved with accumulating experience and the passage of time, and until then we must continue to study and increase our awareness in identifying events and entities that may enhance cancer risk.

\section{REFERENCES}

1. Davies L, Welch HG, 2006 Increasing incidence of thyroid cancer in the United States, 1973-2002. JAMA 295: 2164-2167.

2. Jemal A, Siegel R, Ward E, et al, 2006 Cancer Statistics, CA Cancer J Clin 56: 106-130.

3. Ito J, Noguchi S, Murakami T, Noguchi A, 1980 Factors affecting the prognosis of patients with carcinoma of the thyroid. Surg Gynecol Obstet 150: 539-544.

4. Kesmodel SB, Terhune KP, Canter RJ, et al, 2003 The diagnostic dilemma of follicular variant of papillary thyroid carcinoma. Surgery 134: 1005-1012.

5. Ain KB, 1995 Papillary thyroid carcinoma. Etiology, assessment, and therapy. Endocrinol Metab Clin North Am 24: 711-760.

6. Schlumberger MJ, 1998 Papillary and follicular thyroid carcinoma. N Engl J Med 338: 297-306.

7. Robbins J, Merino MJ, Boice JD Jr, et al, 1991 Thyroid cancer: a lethal endocrine neoplasm. Ann Intern Med 115: 133-147.

8. Hay ID, 1990 Papillary thyroid carcinoma. Endocrinol Metab Clin North Am 19: 545-576.

9. Kashima K, Yokoyama S, Noguchi S, et al, 1998 Chronic thyroiditis as a favorable prognostic factor in papillary thyroid carcinoma. Thyroid 8: 197-202.

10. Loh KC, Greenspan FS, Dong F, Miller TR, Yeo PP, 1999 Influence of lymphocytic thyroiditis on the prognostic outcome of patients with papillary thyroid carcinoma. J Clin Endocrinol Metab 84: 458-463.

11. Mechler C, Bounacer A, Suarez H, et al, 2001 Papillary thyroid carcinoma : 6 cases from 2 families with associated lymphocytic thyroiditis harbouring RET/PTC rearrangements. Br J Cancer 85: 1831-1837.

12. Uchino S, Noguchi S, Kawamoto H, et al, 2002 Familial nonmedullary thyroid carcinoma characterized by multifocality and a high recurrence rate in a large study population. World J Surg 26: 897-902.

13. Larson SD, Jackson LN, Riall TS, et al, 2007 Increased incidence of well-differentiated thyroid cancer associated with Hashimoto thyroiditis and the role of the PI3k/Akt pathway. J Am Coll Surg 204: 764-775.

14. Pal T, Vogl FD, Chappuis PO, et al, 2001 Increased risk for nonmedullary thyroid cancer in the first degree relatives of prevalent cases of nonmedullary thyroid cancer: a hospital-based study. J Clin Endocrinol Metab 86: 5307-5312.

15. Chen AY, Levy L, Goepfert H, Brown BW, Spitz MR, Vassilopoulou-Sellin R, 2001 The development of breast carcinoma in women with thyroid carcinoma. Cancer 92: $225-231$.

16. Garner CN, Ganetzky R, Brainard J, et al, 2007 Increased prevalence of breast cancer among patients with thyroid and parathyroid disease. Surgery 142: 806-813.

17. Polednak AP, 1994 Trends in cancer incidence in Connecticut 1935-1991. Cancer 74: 2863-2872.

18. Goodman MT, Yoshizawa CN, Kolonel LN, 1988 Descriptive epidemiology of thyroid cancer in Hawaii. Cancer 61: 1272-1281.

19. Whelan SL, Parkin DM, Masuyer E, 1990 Patterns of cancer in five continents. IARC Sci Publ 102: 1-159.

20. Ferlay J, Bray F, Pisani P, Parkin DM 2004 Globocan 2002: Cancer incidence, mortality and prevalence worldwide. IARC Cancer Base No. 5, Lyon: IARC Press. 
21. Franceschi S, LaVecchia C, Bidoli E, 1998 High incidence of thyroid cancer in central Italy. Int J Cancer 77: 481-482.

22. Hrafnkelsson J, Jonasson JG, Sigurdsson G, Sigvaldason H, Tulinius H, 1988 Thyroid cancer in Iceland 19551984. Acta Endocrinol (Copenh) 118: 566-572.

23. Liu S, Semenciw R, Ugnat AM, Mao Y, 2001 Increasing thyroid cancer incidence in Canada, 1970-1996: time trends and age-period-cohort effects. Br J Cancer 85: 1335-1339.

24. Hodgson NC, Button J, Solorzano CC, 2004 Thyroid cancer: is the incidence still increasing? Ann Surg Oncol 11: 1093-1097.

25. Burgess JR, 2002 Temporal trends for thyroid carcinoma in Australia: an increasing incidence of papillary thyroid carcinoma (1982-1987). Thyroid 12: 141-149.

26. Truong T, Rougier Y, Dubourdieu, et al, 2007 Time trends and geographic variations for thyroid cancer in New Caledonia, a very high incidence area (1985-1999). Eur J Cancer Prev 16: 62-70.

27. Colonna M, Grosclaude P, Remontet L, et al, 2002 Incidence of thyroid cancer in adults recorded by French cancer registries (1978-1997). Europ J Cancer 38: 1762-1768.

28. Reynolds RM, Weir J, Stockton DL, Brewster DH, Sandeep TC, Strachan MW, 2005 Changing trends in incidence and mortality of thyroid cancer in Scotland. Clin Endocrinol (Oxf) 62: 156-162.

29. Dijkstra B, Prichard RS, Lee A, et al, 2007 Changing patterns of thyroid carcinoma. Irish J Med Sci 176: 87-90.

30. Cardis E, Kesminierne A, Ivanov V, et al, 2005 Risk of thyroid cancer after exposure to 131-I in childhood. J Natl Cancer Inst 97: 724-732.

31. Figge JJ, Jennings T, Gerasimov G, Kartel N, Yarmolinsky D, Ermak G, 2006 Radiation induced thyroid cancer. In Thyroid Cancer: A Comprehensive Guide to Clinical Management, L. Wartofsky and D. Van Nostrand (Eds), Humana Press, Totowa, NJ; pp, 63- 83.

32. Jacob P, Kenigsberg Y, Zvonova I, et al, 1999 Childhood exposure due to the Chernobyl accident and thyroid cancer risk in contaminated areas of Belarus and Russia. Br J Cancer 80: 1461-1469.

33. Kerber RA, Till JE, Simon SL, et al, 1993 A cohort study of thyroid disease in relation to fallout from nuclear weapons testing. JAMA 270: 2076-2082.

34. Conard RA, Dobyns BM, Sutow WW, 1970 Thyroid neoplasia as late effect of exposure to radioactive iodine in fallout. JAMA 214: 316-324.

35. Parker N, Belsky JL, Yamamoto T, Kawamoto S, Keehn RJ, 1974 Thyroid carcinoma after exposure to atomic radiation: a continuing survey of a fixed population, Hiroshima and Nagasaki, 1958-1971. Ann Intern Med 80: 600-604.

36. Imaizumi M, Usa T, Tominaga T, et al, 2006 Radiation dose-response relationships for thyroid nodules and autoimmune thyroid diseases in Hiroshima and Naga- saki atomic bomb survivors 55-58 years after radiation exposure. JAMA 295: 1011-1022.

37. Davis S, Kopecky KJ, Hamilton TE, Onstad L, Hanford Thyroid Disease Study Team, 2004 Thyroid neoplasia, autoimmune thyroiditis, and hypothyroidism in persons exposed to iodine 131 from the Hanford nuclear site. JAMA 292: 2600-2613.

38. Hahn K, Schnell-Inderst P, Grosche B, Holm LE, 2001 Thyroid cancer after diagnostic administration of iodine131 in childhood. Radiat Res 156: 61-70.

39. Dickman PW, Holm LE, Lundell G, Boice JD Jr, Hall P, 2003 Thyroid cancer risk after thyroid examination with 131-I: a population-based cohort study in Sweden. Int J Cancer 106: 580- 587.

40. Holm LE, Hall P, Wiklund K, et al, 1991 Cancer risk after iodine-131 therapy for hyperthyroidism. J Natl Cancer Inst 83: 1072-1077.

41. Sarne D, Schneider AB, External radiation and thyroid neoplasia. Endocrinol Metab Clin North Am 25: 181196.

42. Ron E, Kleinerman RA, Boice JD Jr, LiVolsi VA, Flannery JT, Fraumeni JF Jr, 1987 A population-based case-control study of thyroid cancer, J Natl Cancer Inst 79: $1-12$.

43. Favus MJ, Schneider AB, Stachura ME, et al, 1976 Thyroid cancer occurring as a late consequence of head-and-neck irradiation: Evaluation of 1056 patients. N Engl J Med 294: 1019-1025.

44. Mellemgaard A, From G, Jorgensen T, Johansen C, Olsen JH, Perrild H, 1998 Cancer risk in individuals with benign thyroid disorders. Thyroid 8: 751-754.

45. Herraiz M, Barbesino G, Gaquin W, et al, 2007 Prevalence of thyroid cancer in familial adenomatous polyposis syndrome and the role of screening ultrasound examinations. Clin Gastroenterol Hepatol 5: 367-373.

46. Kent L, McBride R, McConnell R, Neugut AI, Bhagat $\mathrm{G}$, Green PH, 2006 Increased risk of papillary thyroid cancer in celiac disease. Dig Dis Sci 51: 1875-1877.

47. Guignard R, Truong T, Rougier Y, Baron-Dubourdieu D, Guenel P, 2007 Alcohol drinking tobacco smoking, and anthropometric characteristics as risk factors for thyroid cancer: a countrywide case-control study in New Caledonia. Am J Epidemiol 166: 1140-1149.

48. Hovens GC, Stokkel MP, Kievit J, et al, 2007 Associations of serum thyrotropin concentrations with recurrence and death in differentiated thyroid cancer. J Clin Endocrinol Metab 92: 2610-2615.

49. Boelaert K, Horacek J, Holder RL, Watkinson JC, Sheppard MC, Franklyn JA, 2006 Serum thyrotropin concentration as a novel predictor of malignancy in thyroid nodules investigated by fine-needle-aspiration. J Clin Endocrinol Metab 91: 4295-4301.

50. Haymart MR, Repplinger DJ, Leverson GE, et al, 2007 Higher serum TSH level in thyroid nodule patients is associated with greater risks of differentiated thyroid cancer and advanced tumor stage. J Clin Endocrinol Metab 93: 809-814. 